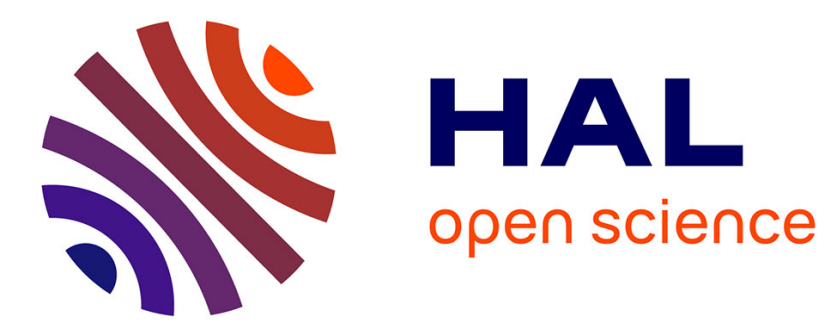

\title{
Magnetic and Mössbauer Investigations of $\mathrm{CoGa2-xFexO4}$
}

Z. Seidov, G. Sultanov, S. Ibragimov, A. Kaplienko

\section{To cite this version:}

Z. Seidov, G. Sultanov, S. Ibragimov, A. Kaplienko. Magnetic and Mössbauer Investigations of CoGa2-xFexO4. Journal de Physique IV Proceedings, 1997, 07 (C1), pp.C1-265-C1-266. 10.1051/jp4:19971103 . jpa-00254724

HAL Id: jpa-00254724

https://hal.science/jpa-00254724

Submitted on 1 Jan 1997

HAL is a multi-disciplinary open access archive for the deposit and dissemination of scientific research documents, whether they are published or not. The documents may come from teaching and research institutions in France or abroad, or from public or private research centers.
L'archive ouverte pluridisciplinaire HAL, est destinée au dépôt et à la diffusion de documents scientifiques de niveau recherche, publiés ou non, émanant des établissements d'enseignement et de recherche français ou étrangers, des laboratoires publics ou privés. 


\title{
Magnetic and Mössbauer Investigations of $\mathrm{CoGa}_{2-x} \mathrm{Fe}_{x} \mathrm{O}_{4}$
}

\author{
Z. Seidov, G. Sultanov, S. Ibragimov and A. Kaplienko*
}

Institute of Physics, Academy of Sciences of Azerbaijan, Baku 370143, Azerbaijan

* B. Verkin Institute for Low Temperature Physics and Engineering, 47 Lenin ave., Kharkov 310164.

Ukraine

\begin{abstract}
The magnetic properties of system $C o G a_{2-n} F e_{x} O_{4}(2=0.1,0.2,0.3,04,0.5,0.8,1)$ with spinel structure were investigated by means of dc susceptibility and dc magnetization measurements in magnetic fields 1-12kOe as well as by means of Mossbauer effect. The results of magnetic measurements show that compounds with $0.1 \leq 2 \leq$ 0.5 exhibit features typical for spin glasses and ones with $x=0.8$ and 1 have a ferromagnetic ordering. The compounds with $x=0.8$ and 1 exhibit relaxation behaviour in their Mossbauer spectra.
\end{abstract}

It is well known that, spinels are good candidates for spin glass behaviour because of the different types of disorder and frustration that may be present in their lattices [1]. In this paper we report results of magnetic (dc susceptibility and de magnetiastion) and Mossbauer meagurements of polycrystalline compounds $\mathrm{CoGa}_{2-x} \mathrm{Fe}_{x} \mathrm{O}_{4}(x=0.1,0.2,0.3$, $04,0.5,0.8,1)$ with spinel structure [2]. The nentron diffraction and low field susceptibility messurements showed that spinel $\mathrm{CoGa}_{2} \mathrm{O}_{4}$ exhibited spin glass behaviour due to the competing interactions between $\mathrm{Co}^{2+}$ ions occuping tetrahedrai (A) and octahedral (B) sites [3].

DC magnetization measurements were performed in the temperature range $4.2 \mathrm{~K} \leq T \leq 300 \mathrm{~K}$ using a Dominicallitype pendulum magnetometer. DC gnsceptibility measurements in the $4.2 \mathrm{~K} \leq \mathrm{T} \leq 600 \mathrm{~K}$ were carried ont using a Faraday method. The applied fields used in these magretic measurements are 1-12kOe. The Mossbauer experiment was made using a gamma-spectrometer working in a regime of constant velocity. The source used was ${ }^{57} \mathrm{Co}$ in stainless steel.

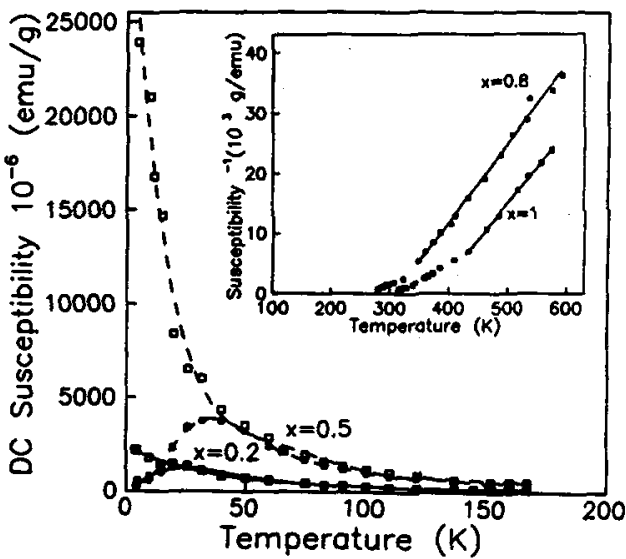

a)

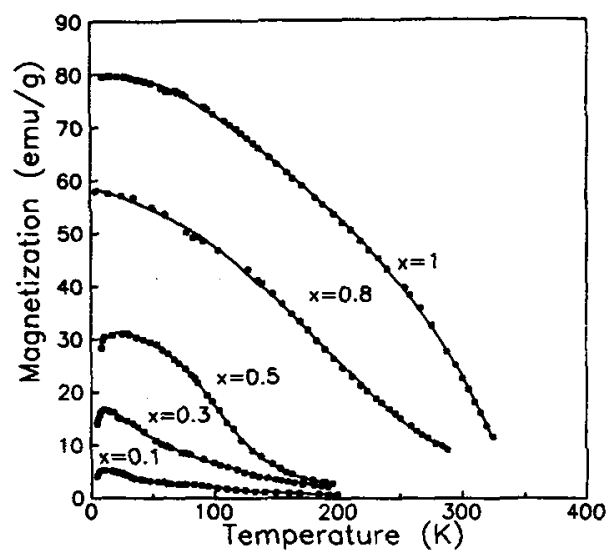

b)

Figure 1. a) Temperature dependence of de susceptiblity (atc-closed squares and fc-open squares) of $\mathrm{CoG}_{\mathrm{a}}-\mathrm{F} \mathrm{F}_{2} \mathrm{O}_{4}$ with $x=0.2$ and 0.5 measured in field $1 . \mathrm{kOe}$. The inset show temperature dependence of the inverse susceptibility for $x=0.8$ and 1 . b) Temperature dependence of the de magnetization of $C O G a_{z-x} F c_{x} O_{4}$ with $x=0.1,0.3,0.5,0.8$, and 1 measured in field $10.8 \mathrm{kOe}$.

In Figure I(x) the temperature dependence of magnetic susceptibility of samples with concentration $z=0.2$ and 0.5 is shown. The samples were first cooled in zero field down to $4.2 K$. The field was applied and the measurementa taken with increasing temperature (afc curve). Then the samples were cooled again in a constant field and a new set 
of measurements done with decreasing temperature (fc curve). DC susceptibility measurements made after cooling the samples in zero field ( $\mathrm{afc}$ ) indicate the presence of anomaly at temperatures $26 \mathrm{~K}$ and $32 \mathrm{~K}$ in the $2=0.2$ and 0.5 respectively. The shape of zic curve and fe curve is indicative of spin glass like behaviour for these samples. Note that the values of the paramagnetic Curie temperature are positive $\theta=102 \mathrm{~K}$ and $\theta=161 \mathrm{~K}$ for $x=0.2$ and $x=0.5$ respectively. Such SG-like behaviour was observed also for samples with $x=0.1,0.3$ and 0.4 . The anomaly observed on the temperature dependence of dc magnetization after cooling in zero field of sarnples with $0.1 \leq x \leq 0.5$ (Figure 1(b) ) confirm spin glass behaviour.

The results of magnetic measurements here reported indicate two type of magnetic behaviour depending on the sample composition. The curves of temperature dependence of inverse magnetic susceptibility (the values of $\theta$ are positive $\theta=315 K, \theta=380$ for $x=0.8$ and 1 respectively) (inset. Figure $1(a)$ ) and magnetization (Figure.1(b)) are indicative of the presence of ferromagnetic ordering in the samples with $z=0.8$ and $1\left(T_{c} \sim 285 \mathrm{~K}\right.$ and $T_{c} \sim 335 \mathrm{~K}$ for $x=0.8$ and 1). The field dependence of magnetization measured on these samples up to $12.2 \mathrm{kOe}$ at temperature $4.2 \mathrm{~K}$ (Figure 2(a)) shows that the behaviour of the curves are different above and below the concentration $x=0.5$.

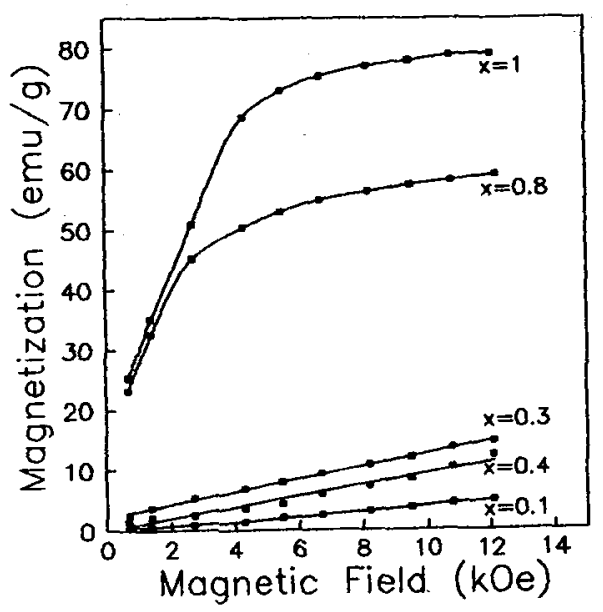

a)

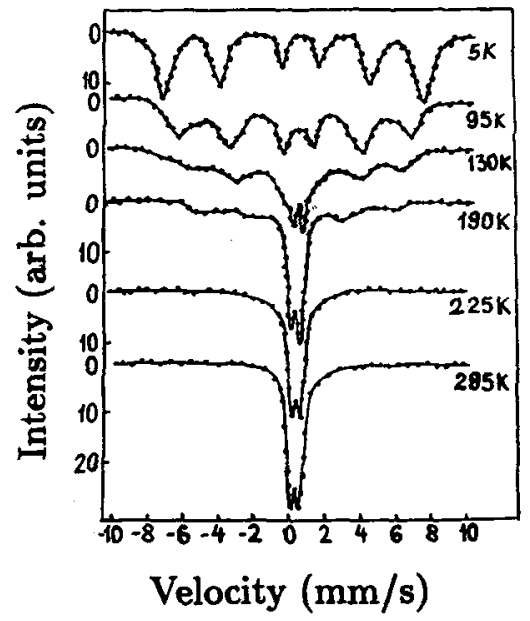

b)

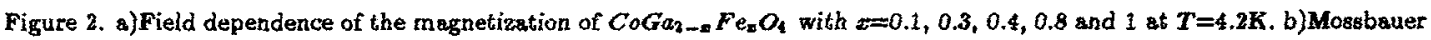
spectra of $\mathrm{CoG}_{a_{1.3}} \mathrm{Fe}_{0.8} \mathrm{O}_{\mathrm{E}}$ in temperature range $5 \mathrm{~K} \leq T \leq 295 \mathrm{~K}$.

Figure 2(b) shows the Mossbaner apectra of $\mathrm{CoGa}_{1.2} F e_{0.8} \mathrm{O}_{4}$ and in temperature range 5K $\leq T \leq 295 \mathrm{~T}$. The Mossbaner spectra in this range have the features characteristic for relaxation effects [4,5]. The relaxation effecta are also observed in the Mossbaner spectra sample with $x=1$ [ 6$]$. The values of isomer shift $\delta \approx 0.5 \pm 0.03 \mathrm{~mm} / \mathrm{s}$ determined from the Mossbauer spectra at room temperature are typical for $F e^{3+}$. The phase transition temperature determined from the Mossbaner messarements for $x=0.8$ is 225K. There is a large difference between phase transition temperature determined by means of magnetic and Mossbauer measurements for $z=0.8, T_{c} \sim 285 K$ and $T_{c} \sim 225 K$ respectively. This large difference can be related to different time scale measurements.

Thus magnetic measurements show that samples with concentration $x \leq 0.5$ are good candidates to exhibit spin glass behaviour. The relaxation effects observed in the Mossbaner spectra. of samples with $x=0,8$ and 1 indicate the presence of the spin fuctuations.

The authors are grateful to Prof. Ya.M.Seidov (IPASA Baku) and Dr. V.Ponarnarchuk (IITPE Kharkov) for useful discussions.

\section{References}

[1] Vilain J., Z.Phys, B33 (1979) 31.

[2] Ibragimov S.G., Sultanov G.D., Guseinov N.G., Shukurov A.S., Dokladi Akademii Nauk Azerb. SSR, 5 (1989) 12.

[3] Soubeyroux J.L., Fiorani D, and Agostinelli E., J.Magn. Magn. Mat., 54-57 (1986) 83.

[4] Iyenger P.K. and Bhragava S.C., Phys.Status Solidi (b) 46 (1971) 117.

[5] Singh M.R. and Bhragava S.C., J.Phys: Condens, Matter 7 (1995) 8183

[6] Sultanov G.D., Seidov Z.Yu., Kaplienko A., Fizika Nizkikh Ternperatar (1996) in press. 